\title{
Redes sociais sobre Transtorno do Espectro Autista no Facebook como suporte interpessoal: implicações nos processos de governança em saúde
}

Social networks about Autism Spectrum Disorder on Facebook as an interpersonal support: implications in the processes of health governance

Redes sociales sobre el Trastorno del Espectro Autista en Facebook como apoyo interpersonal: implicaciones en los procesos de gobernanza de la salud

Robson Celestino Prychodco ${ }^{1, a}$

robsilcel@gmail.com | https://orcid.org/oooo-0003-2070-8076

Zelia Zilda Lourenço de Camargo Bittencourt ${ }^{1, b}$

zeliaz@terra.com.br | https://orcid.org/0000-0002-6796-5515

${ }^{1}$ Universidade Estadual de Campinas, Faculdade de Ciências Médicas. Campinas, SP, Brasil.

a Mestrado em Saúde, Interdisciplinaridade e Reabilitação pela Universidade Estadual de Campinas.

${ }^{\text {b }}$ Doutorado em Saúde Coletiva pela Universidade Estadual de Campinas.

\section{Resumo}

A formação de Redes Sociais Virtuais (RSVs) em comunidades como o Facebook tornou-se um importante instrumento de busca por socialização e informação. Este artigo apresenta dados sobre fontes de informação utilizadas por responsáveis de crianças com Transtorno do Espectro Autista (TEA) e como essas interferem na percepção de suporte interpessoal e nos processos de governança em saúde. No estudo quantitativo, participaram 90 membros das três maiores RSVs sobre TEA. Para a coleta de dados foi utilizado questionário semiestruturado, cujas respostas foram quantificadas para melhor visualização. Os resultados demonstraram que a participação nessas redes é a principal fonte de informação para metade dos participantes, especialmente para a parcela da população com menor renda; 70/90 voluntários informaram se sentir amparados pelos parceiros de RSV e 63/90 se sentem desamparados pela sociedade em geral. Este fenômeno pode ser explicado pela formação de laços sociais marcados pela reciprocidade de situações vividas.

Palavras-chave: Rede social; Governança clínica; Relações interpessoais; Transtorno do espectro autista; Apoio social. 


\begin{abstract}
The formation of Virtual Social Networks (RSVs) in communities as Facebook has become an important tool for searching for socialization and information. This article presents data on the sources of information used by those responsible for children with Autism Spectrum Disorder (ASD), and how they interfere in the perception of interpersonal support and health governance processes. In the quantitative study, 90 members from the 3 largest RSVs on ASD participated. For the data collection, a semi-structured questionnaire was used. Responses were quantified to facilitate visualization of the data. The results showed that participation in these networks is the main source of information for half of the participants, especially for the portion of the population with lower income; 70/90 volunteers reported feeling supported by RSV partners and 63/90 reported feeling helpless by society in general. A phenomenon that can be explained by the formation of social bonds marked by the reciprocity of lived situations.
\end{abstract}

Keywords: Social network; Clinical governance; Interpersonal relations; Autism spectrum disorder; Social support.

\title{
Resumen
}

La formación de Redes Sociales Virtuales (RSVs) en comunidades como Facebook se ha convertido en un importante instrumento de búsqueda de socialización e información. Este artículo presenta datos sobre fuentes de información utilizadas por responsables de niños con trastorno del espectro autista (TEA), y cómo interfieren en la percepción de soporte interpersonal y en los procesos de gobernanza en salud. Se trató de estudio cuantitativo, participaron 90 miembros de las 3 mayores RSVs sobre TEA. Para la recolección de datos se utilizó un cuestionario semiestructurado. Las respuestas se cuantificaron para facilitar la visualización de los datos. Los resultados demostraron que la participación en esas redes es la principal fuente de información para la mitad de los participantes, especialmente para la parcela de la población con menores ingresos; 70/90 voluntarios informaron sentirse amparados por los socios de RSV y 63/90 informaron sentirse desamparados por la sociedad en general. Fenómeno que puede ser explicado por la formación de lazos sociales marcados por la reciprocidad de situaciones vividas.

Palabras clave: Red social; Gestión clínica; Relaciones interpersonales; Trastorno del espectro autista; Apoyo social.

Contribuição dos autores:

Concepção e desenho do estudo: os autores elaboraram o artigo de modo equitativo.

Aquisição, análise ou interpretação dos dados: as etapas foram realizadas conjuntamente.

Redação do manuscrito: o manuscrito foi escrito e revisado pelos dois autores.

Revisão crítica do conteúdo intelectual: a revisão crítica foi feita pelos dois autores.

Declaração de conflito de interesses: não há.

Fontes de financiamento: não houve.

Considerações éticas: o protocolo da investigação foi aprovado pelo Comitê de Ética em Pesquisa da Faculdade de Ciências Médicas da Universidade Estadual de Campinas, sob parecer nº.793.914, conforme Resoluções 466/12 e 510/2016 do Conselho Nacional de Saúde.

Agradecimentos/Contribuições adicionais: não há.

Histórico do artigo: submetido: 19 dez. 2018 | aceito: 30 jul. 2019 | publicado: 20 dez. 2019.

Apresentação anterior: não houve.

Licença CC BY-NC atribuição não comercial. Com essa licença é permitido acessar, baixar (download), copiar, imprimir, compartilhar, reutilizar e distribuir os artigos, desde que para uso não comercial e com a citação da fonte, conferindo os devidos créditos de autoria e menção à Reciis. Nesses casos, nenhuma permissão é necessária por parte dos autores ou dos editores. 


\section{Introdução}

A ampliação do acesso à tecnologia e à internet proporcionou a comunicação entre as pessoas em tempo real a partir de qualquer ponto geográfico com acesso à internet, fenômeno nomeado de "sociedade em rede". Essa nova forma de interação facilita o encontro entre indivíduos que vivenciam ou vivenciaram situações similares nas mais distintas regiões geográficas. $\mathrm{O}$ uso da internet possibilita que pessoas com interesses comuns se encontrem, criando Redes de interação com base na reciprocidade de situações vividas².

A participação nas Redes Sociais Virtuais (RSVs) tem ampliado e ressignificado as formas de socialização, levando seus usuários a interagir constantemente no meio virtual. Em decorrência da ampliação do número de usuários desses espaços, é provável que tal mudança de comportamento social se configure como uma tendência.

Segundo Hall ${ }^{3}$, no contexto da Comunicação Mediada pela Internet (CMI) existem apenas dois tipos de interação que se diferenciam pela forma de relacionamento mantido, a saber: 1- Interação mútua, caracterizada por relações interdependentes e processos de negociação, em que cada interagente participa da construção inventiva e cooperada da relação; 2- Interação reativa, limitada por relações que vão determinar os estímulos e respostas.

A participação nas RSVs faz emergir novas formas de comunicação e complexos padrões de sociabilidade, podendo influenciar processos relacionados à governança em saúde ${ }^{4}$, com ressignificações nas formas de interação ${ }^{3,5}$ entre usuários dos serviços e entre estes e os profissionais de saúde.

Nesse artigo são apresentadas as principais fontes de informação, a percepção de suporte interpessoal, bem como possíveis implicações da organização de pessoas em RSVs para os serviços de saúde.

A literatura informa acerca do empoderamento ${ }^{6}$ dos pacientes frente aos processos de saúde/doença e o processo de surgimento do paciente informado ${ }^{7,8}$ definido como aquele que "conquistou habilidades e conhecimentos necessários para desempenhar um papel ativo nos processos de decisão que envolvem sua saúde e a gestão de suas condições de vida" , uma vez que a dinâmica e a vinculação social das interações mútuas que acontecem em RSVs repercutem nas políticas e práticas de saúde³.

Para a escolha das RSVs do Facebook, foi realizado um levantamento na seção: 'Procurar pessoas, locais e coisas' utilizando-se a palavra-chave 'Autismo'. Foram selecionadas as 3 RSVs com o maior número de membros, onde participavam familiares, profissionais da saúde, educação, assistência social, ativistas dos direitos humanos e pessoas interessadas em temas relacionados à qualidade de vida das pessoas com Transtorno do Espectro Autista (TEA).

O Dicionário de Saúde Mental em sua $5^{\mathrm{a}}$ edição ${ }^{9}$ agrupou as denominações: Autismo, Transtorno Desintegrativo da Infância, Transtorno global do desenvolvimento e a Síndrome de Asperger em apenas uma, nomeada Transtornos do Espectro Autista, classificando-as dentro de um espectro que inclui os quadros leves, moderados e graves. Segundo esse documento, o Espectro tem início precoce e leva a alterações que limitam a funcionalidade do indivíduo, implicando em déficits persistentes nas áreas de comunicação e interação social, padrões repetitivos e interesses restritos de comportamento e atividades.

Segundo Sprovieri ${ }^{10} \mathrm{e}$ Sanchez ${ }^{11}$, no percurso que se segue ao diagnóstico, a família se sente impotente em sua função socializadora e incapaz de realizar o que é socialmente esperado dela, uma vez que passa a conviver com distintas dificuldades, como a cronicidade da doença e o julgamento de pessoas pouco acolhedoras, causandolhes sintomas que geram constrangimento social e rompimento dos vínculos e atividades do cotidiano.

Por falta de conhecimento e informação, muitas vezes, familiares, amigos e vizinhos exercem influência negativa, fazendo julgamentos e críticas sem embasamento científico. Questionam as formas de cuidado da família ou sugerem tratamentos de maneira inconsequente, até mesmo sugerindo que crises sensoriais, por exemplo, se tratam de 'birras' das crianças ou de falta de capacidade para ensinar por parte dos responsáveis. Isso acaba por reforçar o estigma da incompetência parental que, em muitos casos, a família já carrega, causando tensões e desgaste emocional ${ }^{11}$. 
A dificuldade de compreender a criança/adolescente com TEA somada aos rituais e estereotipias, não raramente, levam as famílias ao isolamento social, ao afastamento de amigos e familiares. Tal fato permite aos pesquisadores afirmar que o transtorno influencia todo o grupo familiar, gerando rompimentos nas atividades sociais ${ }^{11}$.

Diante desse sentimento de isolamento social que, muitas vezes, as famílias com indivíduos com TEA experimentam, nasce a necessidade de buscar outros meios de comunicação, participação, interação social, acolhimento e informação. Nesse contexto surgem as RSVs sobre TEA na Comunidade do Facebook.

\section{Redes sociais virtuais e a busca por informação e socialização}

Diferentemente de Comunidade Virtual ${ }^{2}$, que é definida como o total de membros de determinado espaço virtual, as RSVs são formadas apenas por aqueles que interagem entre si e que contribuem ativamente para o desenvolvimento dos tópicos abordados.

Tal interação oferece o potencial de formação de laços que, muitas vezes, podem transcender os espaços virtuais. As RSVs estão inseridas no contexto da CMI, e sua influência é notória a partir da socialização do acesso à Rede Mundial de Computadores (RMC). Inicialmente essa rede era utilizada apenas para transmissão de dados. Contudo, após a estruturação da RMC, foram desenvolvidos inúmeros programas destinados à comunicação entre pessoas ${ }^{12,13}$.

Segundo Castells ${ }^{1}$, sob certas circunstâncias, o uso da internet pode servir como um substituto para outras atividades sociais, até mesmo estimulando as interações presenciais. No que diz respeito à formação comunitária, o autor acrescenta que a internet altera os limites dessa organização, uma vez que amplia a formação de grupos a partir de interesses comuns para além dos limites espaciais, o que consequentemente diminui as influências do meio social sobre o grupo e amplia o caráter de suporte aos indivíduos que compõem uma rede virtual.

Essas interações têm o potencial de construir laços sociais, definidos como conexões apresentadas entre pessoas em uma RSV. Tais relações são constituídas por indivíduos e seus pares, formando redes virtuais de relações pessoais ${ }^{14}$.

Para Granovetter ${ }^{15}$, os laços sociais podem se distinguir entre fracos e fortes. O primeiro tipo é caracterizado por vínculos mais fluídos, já o segundo é marcado por maior proximidade entre as pessoas. Grosso modo, vínculos familiares podem ser entendidos como fortes, e vínculos com os demais participantes em uma RSV, por exemplo, são constituídos por laços fracos. Ao analisar as contribuições desse autor sobre a formação dos laços sociais nas Comunidades Virtuais, Kaufman ${ }^{16}$ concorda que no ciberespaço predominam os laços fracos, uma vez que predominam conexões com diversos grupos simultaneamente. O que pode dar acesso a uma rede de interações e conhecimento maior do que aquela proporcionada pelos vínculos por laços fortes, uma vez que esses se originam em relações mais restritas, marcadas pela formação de uma 'identidade comum', muito próxima ao conceito de círculo familiar.

Transformações no campo da tecnologia e das condições de acesso ao sistema mundial de informação têm impulsionado novos comportamentos quanto ao modo como as pessoas buscam informação e interação. Nesse contexto, cresce o número de usuários dos sistemas de saúde que buscam informação e interação com pares na internet, e esse movimento tem impulsionado a formação de RSVs sobre saúde, que discutem temas ligados à busca por melhores condições de saúde e de qualidade de vida.

A partir da leitura de Goffmann ${ }^{17}$, é possível afirmar que tais responsáveis têm a necessidade de conhecer famílias com experiências semelhantes, fenômeno intitulado por ele de 'grupo dos informados'.

Essa busca pela interação se pauta pelo vínculo gerado pela similaridade de situações vividas pelos familiares ${ }^{2}$, formando laços sociais ${ }^{14}$ e "Capital Social"18, que segundo Bourdieu é definido como a somatória dos recursos individuais, que surgem nas relações entre as pessoas de um mesmo grupo e que pode ser acessado por qualquer um dos integrantes. Nessas redes, o Capital Social produzido por meio 
das contribuições individuais pode ser acessado por qualquer membro que compartilhe o espaço virtual, reafirmando o caráter recíproco da estrutura das RSVs.

Embora o conceito de Capital Social tenha sido definido por Bourdieu em outro contexto social e histórico, é possível utilizá-lo no âmbito da CMI, uma vez que ele se refere às formas de organização dos sujeitos e à maneira como se apropriam do conhecimento construído coletivamente.

Esse Capital Social é heterogêneo e pode assumir categorias relacionais, que representam a soma das relações, laços de uma rede. Tal constructo se dá a partir das interações pautadas pela reciprocidade e confiança entre seus membros, o que oferece potencial para o empoderamento daqueles que interagem nas RSVs ${ }^{2,6}$.

\section{Empoderamento e governança em saúde}

Embora alguns pesquisadores afirmem que o educador Paulo Freire tenha sido o primeiro a utilizar a palavra empoderamento, Roso e Romanini ${ }^{19}$ informam que, na perspectiva do próprio Paulo Freire, o termo surgiu em 1964, tendo sido criado por professores do Instituto Superior de Estudos Brasileiros. Segundo Valoura $^{6}$, empoderamento relaciona-se com os significados de conquistar, superar, avançar, tornar-se sujeito ativo do processo, mas também pode ser entendido como a capacidade de gerar processos que levem a mobilizações e práticas diferenciadas com o propósito de impulsionar grupos e comunidades para a melhoria de suas condições de vida, aumentando sua autonomia.

No contexto da internet, a socialização que ocorre entre os participantes no âmbito das RSVs tem o potencial de aumentar sua capacidade argumentantativa perante os profissionais de saúde que acompanham as crianças e adolescentes com TEA, uma vez que diversos temas são discutidos exaustivamente por uma imensa gama de participantes que vivenciam ou vivenciaram situações semelhantes.

Dentre as mudanças que podem ocorrer no comportamento dos usuários de saúde a partir do empoderamento que ocorre nas RSVs, Garbin, Pereira e Guilam ${ }^{20}$ citam que o "paciente informado" pode transformar a relação entre o profissional de saúde e o paciente, antes centrada na autoridade dos profissionais e no saber médico.

Segundo Santos ${ }^{21}$ e Rosenau ${ }^{22}$, um paciente informado tem sua autoestima e confiança aumentadas. Outro reflexo relacionado ao acesso à informação por meio da internet diz respeito à redução do número de vezes que o paciente recorre ao sistema de saúde ${ }^{23}$. Desse modo, o uso desses novos espaços de busca por informação no âmbito da CMI se consolida como uma nova estratégia à procura de informação em saúde e qualidade de vida, alterando as formas de governança que se estabelecem entre os usuários e os serviços de saúde.

Para autores como Melo5, governança relaciona-se ao modo do Estado elaborar e implementar as políticas públicas, contudo, para $\operatorname{Santos}^{21}$, a governança não se restringe à ação do Estado, incorpora também a ação de grupos como partidos políticos e grupos de pressão, redes sociais informais, hierarquias e associações colaborativas que possibilitam formas de articulação, organização e cooperação específicas com o propósito de satisfazer as demandas de seus usuários. Ao analisar as contribuições da literatura, Smith ${ }^{24}$ informa que estamos deixando o modelo de saúde da "Era Industrial" e ingressando no modelo da "Era da Informação". Segundo esse autor, o modelo da era industrial é fortemente centrado no profissional, enquanto o modelo da "Era da informação" é marcado pelo autocuidado e pela influência da família, das redes sociais e dos amigos.

Um aspecto importante para a mudança de comportamento dos usuários de saúde é a comunicação entre pares na internet, o que gera informação e oferece potencial para que os membros da RSV deixem a posição de meros receptores de conteúdo e passem a contribuir para o desenvolvimento dos tópicos.

Isso nos leva às contribuições de Hall ${ }^{3}$ acerca da recepção, para quem a comunicação pode ser classificada em três tipos que envolvem codificação/decodificação, a saber: 1- Dominância; 2- Negociação e 3- Oposição. No primeiro tipo, o destinatário da mensagem a recebe como o emissor a transmitiu, sem prender-se numa interpretação mais crítica. Na negociação, à priori, o destinatário não demonstra inclinação para aceitar ou 
recusar o ponto de vista do emissor, na hipótese de haver uma relação hierárquica, o autor reconhece que a dominância pode prevalecer. Já a oposição se dá quando a mensagem é compreendida pelo receptor, mas é interpretada em termos diversos da intenção do emissor³.

Segundo Costa ${ }^{25}$, o modelo de Hall representou uma profunda ruptura no campo das teorias sobre a comunicação de massa, uma vez que trouxe à tona elementos da recepção que diziam respeito à percepção dos destinatários e à forma como interagem e decodificam a mensagem, consolidando a lógica de que os receptores não devem ser considerados seres passivos frente à intenção comunicacional.

Assim, cabe apresentar e discutir como se dá a comunicação nas RSVs e como os participantes decodificam as informações em saúde a que têm acesso, demonstrando como a interação (mútua ou reativa) contribui para a consolidação dos conhecimentos compartilhados por meio da dominância, negociação ou oposição, o que oferece potencial para influenciar formas de governabilidade em saúde.

\section{Sujeitos e métodos}

Para a escolha das RSVs do Facebook, foi realizado levantamento na seção: 'Procurar pessoas, locais e coisas' utilizando-se a palavra-chave 'Autismo'. Foram selecionadas as 3 RSVs com o maior número de membros, sendo eles, familiares, profissionais da saúde, educação, assistência social, ativistas dos direitos humanos e pessoas interessadas em temas relacionados à qualidade de vida das pessoas com TEA.

Foram selecionados para participar do estudo membros das três maiores RSVs do Facebook organizadas para socializar informações sobre TEA, a saber: 1 - 'Síndrome de Asperger-Autismo infantil', com 24.731 membros; 2 - ‘Autismo/Asperger/São Paulo', com 10.102 participantes; e 3 - ‘Autismo - Nos bastidores da vida real', com 10.040 membros.

Após a pesquisa ter sido aprovada pelas moderadoras, os participantes foram convidados a partir de um post dos pesquisadores. Quanto aos critérios de inclusão, os participantes deveriam ser responsáveis por crianças e adolescentes com TEA, com idades entre 4 e 17 anos, membros de pelo menos uma das 3 RSVs selecionadas e responder ao questionário integralmente.

Ao aceitarem participar, os voluntários eram redirecionados a uma plataforma específica, em que visualizavam o Termo de Consentimento Livre e Esclarecido e o questionário, que ficaram disponíveis pelo período de 2 meses, entre janeiro e março de 2016.

O instrumento de coleta de dados era composto por 49 questões abertas ou de múltipla escolha, que versavam sobre diversos temas ligados à inclusão social, educacional, fontes de informação e relações interpessoais na percepção de responsáveis por crianças com TEA. Os dados aqui apresentados dizem respeito às fontes de informação e sua relação com a percepção de suporte interpessoal dos participantes, bem como possíveis implicações para os serviços de saúde e seus profissionais.

\section{Resultados}

Foram registradas 218 contribuições, sendo que foram excluídas 128 respostas por não atenderem integralmente aos critérios de inclusão. Ao final da leitura do material coletado, restaram 90 respostas que atenderam aos critérios de inclusão e foram consideradas para a análise de dados.

As RSVs selecionadas para o estudo são formadas pelas interações entre seus membros, marcadas pelo vínculo por meio das diversas formas de comunicação e da capacidade de organização sobre o fazer, proporcionando um sentido à vida, favorecendo a construção de uma identidade e viabilizando a percepção de suporte interpessoal, promovendo o êxito nas ações sociais e no autocuidado, reiterando dados já identificados na literatura ${ }^{26}$.

Os participantes ressaltaram a importância do suporte dado pelos pares das RSVs relativamente à aceitação da deficiência, à superação do "luto pela perda do filho ideal", à importância da socialização de 
conhecimentos relacionados à saúde, inclusão social e escolar, assistência social, legislação e atividades de vida diária. Tudo isso contribui para a reorganização da vida pós-diagnóstico e para a construção de laços sociais, concordando com a literatura sobre o tema, favorecendo a busca por novas possibilidades para o futuro e para a reacomodação de sonhos e projetos ${ }^{6}$.

Quanto à sensação de acolhimento, dentre os 90 participantes, 70 informaram se sentirem amparados pelos pares de RSVs, enquanto apenas 27 citaram o mesmo sentimento com relação à sociedade em geral, o que demonstra a força das interações entre pares nas redes virtuais.

Questionados sobre as suas fontes de informação sobre TEA, os participantes citaram as seguintes categorias: Internet e RSVs; Médicos e terapeutas; Livros e artigos científicos; Professores e Coordenador Pedagógico; Amigos e familiares. Tais dados foram cruzados com a região de origem, renda e idade dos participantes.

Tabela 1 - Fontes por região

\begin{tabular}{lcccccc}
\hline & Sudeste & Sul & Nordeste & $\begin{array}{c}\text { Centro } \\
\text { Oeste }\end{array}$ & Norte & $\begin{array}{c}\text { Total de } \\
\text { participantes } \\
\text { por categoria }\end{array}$ \\
Internet/ RSVs & 30 & 10 & 3 & 1 & 1 & 45 \\
Médicos/ Terapeutas & 19 & 3 & 3 & 2 & 0 & 27 \\
Livros/ artigos científicos & 8 & 4 & 1 & 0 & 0 & 13 \\
Professores e Coordenador Pedagógico & 1 & 1 & 0 & 0 & 0 & 2 \\
Amigos e Familiares & 1 & 0 & 0 & 0 & 0 & 1 \\
Ignoradas & 2 & 0 & 0 & 0 & 0 & 2 \\
Total de participantes por região & $\mathbf{6 1}$ & $\mathbf{1 8}$ & $\mathbf{7}$ & $\mathbf{3}$ & $\mathbf{1}$ & $\mathbf{9 0}$ \\
\hline
\end{tabular}

Fonte: Os autores (2019).

Como demonstrado na Tabela 1, os maiores contingentes de participações encontram-se nas regiões Sudeste e Sul. Alguns fatores podem explicar esse resultado, como o fato de na primeira região concentrar-se o maior contingente populacional do país, conforme dados do IBGE, associado ao fato de uma das RSVs destinar-se especificamente ao Estado de São Paulo. Outro fator importante diz respeito ao acesso à internet. Conforme dados do $\mathrm{IBGE}^{27}$, no ano de 2016, 69,3\% dos domicílios brasileiros dispunham desse recurso. Por região, são identificados os seguintes índices de acesso à RMC: Sudeste com 76,7\%; Centro-oeste com 74,7\%; Sul com 71,3\%; Norte com 62,4\% e Nordeste com 56,6\% de domicílios com internet.

Os dados permitiram observar que as RSVs/internet são as principais fontes de informação para 45 dos 90 voluntários, com preponderância na maioria das regiões do país, com ênfase para as regiões Sul e Sudeste onde a internet encontra-se disponível em um percentual maior de domicílios, excetuando-se a região Norte, na qual não houveram dados que pudessem sustentar essa inferência. Embora essas regiões concentrem as cidades com os melhores índices de desenvolvimento humano (IDH), com maior acesso aos serviços nas áreas da saúde, os participantes também referiram a internet e a participação nas RSVs como sua principal fonte de informação.

Ao relacionar os dados acerca da renda familiar com a fonte de informação sobre TEA, observou-se que as RSVs/internet permaneceram como a principal fonte de informação para os participantes da maioria das faixas de renda, especialmente para aqueles com menor renda, exceto a de 9 a 12 salários mínimos, como pode ser observado na tabela a seguir, uma vez que nessa categoria os participantes informaram que os médicos são as principais fontes de informação. 
Tabela 2 - Fonte de informação sobre TEA por faixa de renda

\begin{tabular}{|c|c|c|c|c|c|}
\hline & de 1 a $4 *$ & de 5 a 8 & de 9 a 12 & mais de 13 & $\begin{array}{l}\text { Total de participantes por } \\
\text { fonte de informação }\end{array}$ \\
\hline Internet / RSVs & 20 & 17 & 4 & 4 & 45 \\
\hline Médicos & 12 & 5 & 8 & 2 & 27 \\
\hline Livros/ Artigos científicos & 5 & 4 & 3 & 1 & 13 \\
\hline $\begin{array}{l}\text { Professores/ Coordenador } \\
\text { Pedagógico }\end{array}$ & 2 & 0 & 0 & 0 & 2 \\
\hline Amigos/ familiares & 1 & 0 & 0 & 0 & 1 \\
\hline $\begin{array}{l}\text { Total de participantes } \\
\text { por faixa de renda }\end{array}$ & 40 & 26 & 15 & 7 & 88 \\
\hline
\end{tabular}

* Considera-se o valor do salário mínimo no ano de 2015 , R\$788,00.

Dois participantes optaram por não responder a essa pergunta.

Fonte: Os autores (2019).

Ao relacionar os dados da principal fonte de informação com a idade, percebe-se que, embora o uso da internet/redes sociais permaneça como a principal fonte de informação em todas as faixas de idade pesquisadas, boa parte dos responsáveis com idades entre 30 e 49 anos consideraram os profissionais da saúde como boas fontes de informação. Na faixa etária entre 40 e 49, as fontes internet/redes sociais e profissionais da saúde se aproximam, como pode ser observado na Tabela 3, a seguir:

Tabela 3 - Fonte de informação dos participantes sobre TEA por idade

\begin{tabular}{|c|c|c|c|c|c|c|}
\hline Idade em anos & $\begin{array}{l}\text { Profissionais } \\
\text { da Escola }\end{array}$ & $\begin{array}{l}\text { Profissionais } \\
\text { da Saúde }\end{array}$ & $\begin{array}{l}\text { Internet/ } \\
\text { RSVs }\end{array}$ & $\begin{array}{l}\text { Amigos e } \\
\text { familiares }\end{array}$ & $\begin{array}{l}\text { Revistas, } \\
\text { livros e artigos } \\
\text { científicos }\end{array}$ & $\begin{array}{l}\text { Número de } \\
\text { participantes por } \\
\text { faixa de idade }\end{array}$ \\
\hline de 20 a 29 & 0 & 3 & 5 & 0 & 1 & 9 \\
\hline de 30 a 39 & 1 & 8 & 23 & 1 & 10 & 43 \\
\hline de 40 a 49 & 1 & 12 & 14 & 0 & 1 & 28 \\
\hline de 50 a 59 & 0 & 2 & 3 & 1 & 1 & 7 \\
\hline mais de 60 & 0 & 2 & 0 & 0 & 0 & 2 \\
\hline $\begin{array}{l}\text { Total de } \\
\text { citações por } \\
\text { categoria }\end{array}$ & 2 & 27 & 45 & 2 & 13 & 89 \\
\hline
\end{tabular}

Um participante optou por não responder a essa pergunta.

Fonte: Os autores (2019).

Mesmo as RSVs/internet tendo mantido preponderância na maioria das faixas de renda, fontes mais tradicionais, como os livros, ainda têm seu espaço. Observa-se que todas as faixas citaram 'Livros e artigos científicos'. Nota-se que a necessidade de informação faz com que esses responsáveis busquem, por vários meios, obter os conhecimentos necessários para cuidar de um membro da família com TEA, principalmente os responsáveis da faixa etária entre os 30 e 39 anos. 


\section{Suporte interpessoal}

De acordo com os dados obtidos na investigação quanto à percepção de suporte interpessoal, fica clara a função exercida pelas RSVs na internet, uma vez que dos 90 participantes, 70 declararam sentir-se, de alguma forma, amparados pelos parceiros de rede social.

Tabela 4 - Percepção de suporte interpessoal

\begin{tabular}{lcccc}
\hline & $\begin{array}{c}\text { Completamente } \\
\text { desamparado }\end{array}$ & Desamparado & Amparado & $\begin{array}{c}\text { Completamente } \\
\text { amparado }\end{array}$ \\
Médicos & 13 & 13 & 29 & 35 \\
Profissionais da Escola & 19 & 13 & 32 & 26 \\
$\begin{array}{l}\text { Família (pessoas que } \\
\text { moram com você) }\end{array}$ & 5 & 8 & 19 & 58 \\
Demais familiares & 22 & 19 & 21 & 28 \\
Sociedade & 45 & 18 & 22 & 5 \\
Amigos & 21 & 15 & 37 & 17 \\
Parceiros de RSVs & 12 & 8 & 18 & 52 \\
& & & Total de respostas & $\mathbf{9 0}$ \\
\hline
\end{tabular}

Fonte: Os autores (2019).

Verificou-se nesse tópico que os maiores índices de apoio na categoria ‘Completamente amparado' se referiram à 'Família', a qual fornece a maior sensação de suporte na percepção dos participantes, sendo lembrada por 58 deles, seguida por 'Parceiros de rede social', com 52 citações, conforme demonstrado na Tabela 4. Já na categoria 'Completamente desamparado', os piores índices referiram-se a 'Sociedade', 'Demais familiares e amigos' e 'Profissionais da escola'. Esses dados ressaltaram a importância da CMI para a vida das famílias com pessoas com TEA.

No outro extremo, nota-se a dificuldade da sociedade (em geral) em lidar com a diferença. Apesar das várias políticas inclusivas já existentes, salta aos olhos a altíssima sensação de desamparo. Cabe então a seguinte pergunta: Como esses responsáveis podem sentir-se mais amparados por pessoas que sequer conhecem pessoalmente? Uma possibilidade de resposta é trazida pela literatura quando explica que a construção dos laços sociais não depende da proximidade física, mas sim da singularidade de situações vivenciadas ${ }^{2}$ e socializadas pelas famílias nas RSVs na internet, elevando a sensação de suporte interpessoal.

A sensação de suporte interpessoal marcada pela reciprocidade de situações vividas e pelo enfrentamento das comorbidades relacionadas aos TEA pode colocar em causa a conclusão de Granoveter ${ }^{15}$, quando informa que nas RSVs predominam laços fracos. Uma vez que os participantes sentem-se acolhidos pelos parceiros de RSVs, tanto quanto o sentem pela família, abre-se a possibilidade de os laços fracos tornarem-se fortes.

\section{Possíveis implicações da participação nas RSVs: paciente informado e mudanças nos processos de governança. Novas relações entre usuários dos serviços de saúde e entre esses e os profissionais}

Nesse espaço são apresentados os principais temas discutidos nas RSVs e a relação que estabelecem com o empoderamento ${ }^{6}$ dos participantes, com os processos de governança em saúde ${ }^{4}$ e com as mudanças de atitude dos participantes perante os profissionais de saúde. 
Devido ao acesso e à intensa propagação da informação nas RSVs e à troca de experiências significativas que acontecem no interior das redes, é possível que os responsáveis por crianças com TEA sintam-se mais preparados para questionar profissionais de saúde, educação e de outras áreas, conheçam melhor as garantias legais que as pessoas com TEA possuem e sintam-se em condições para exigí-las, deslocando-se de uma posição meramente passiva frente aos profissionais de saúde para a posição do "paciente informado", .

Tal fato, por um lado, pode colocar os usuários das RSVs em risco, uma vez que nem todas as informações que circulam nesse ambiente virtual têm fontes confiáveis, reforçando a importância dos profissionais de saúde enquanto propagadores de informações de qualidade. Essa situação pode representar para estes um imenso desafio no sentido de convencer o paciente de que nem todas as informações obtidas na internet são seguras ou adequadas para a sua situação, gerando até mesmo tensões entre pacientes e profissionais de saúde. Por outro lado, pode impulsionar processos de melhoria dos sistemas de saúde, alterando formas de governança local e dando origem a novas políticas públicas da área.

Os tópicos discutidos nas RSVs, segundo os participantes, dizem respeito ao acolhimento dos responsáveis que se encontram em fase de diagnóstico e daqueles que acabaram de concluí-lo, divulgação de eventos, cursos, palestras, encontros de pessoas com TEA, atividades de vida diária (AVD), dicas de livros, filmes, artigos científicos, troca de experiências com o uso de medicamentos, tratamentos e terapias.

Assim, os profissionais de saúde deixam o lugar central, tornando-se parceiros, orientadores, facilitadores da busca por saúde e qualidade de vida, deslocando o ponto central do saber médico para o saber que é construído a partir do Capital Social ${ }^{18}$, cuja origem é o compartilhamento de informações e experiências entre pares nas RSVs, fenômeno que, se bem compreendido, pode gerar melhorias dos sistemas de governança ${ }^{4}$ em saúde, por meio da corresponsabilização dos processos de saúde/doença entre paciente e profissionais. Desse modo, as trocas de informação, conhecimento e experiências influenciam mudanças de comportamento dos usuários e profissionais de saúde.

\section{Discussão}

Ao longo dos últimos anos, temos visto uma verdadeira revolução no que diz respeito ao acesso à informação em diversas áreas do conhecimento e à reconfiguração das formas de socialização. Nesse novo contexto, a internet tem adquirido cada vez mais espaço na forma como as pessoas buscam informação e interação em diversas áreas como a saúde e a educação.

Oempoderamento que acontece durante essa troca de informações gera um comportamento mais atuante, participativo e questionador por parte dos usuários dos sistemas de saúde, que passam a desempenhar um papel mais ativo no processo de decisão que envolve a saúde e a qualidade de vida das crianças com TEA.

É necessário reconhecer essa nova forma de busca por interação e informação para distinguir seus efeitos, monitorar, avaliar e gerir as transformações que ocorrem no âmbito das políticas públicas, práticas de intervenção em saúde e das mudanças nos comportamentos dos usuários e dos profissionais de saúde, o que oferece potencial para redefinir formas de governança, como já alertou Smith ${ }^{24}$.

Relativamente às mudanças de comportamento dos usuários de saúde, destaca-se a questão do empoderamento do cidadão, derivado da obtenção e compartilhamento de informações disponíveis na internet e discutidas nas RSVs por pares. Forma-se, então, um conjunto de conteúdos e informações que podem ser compartilhados e utilizados por todos os membros, criando uma espécie de capital social, o que, de certo modo, tem o potencial de gerar processos de melhoria da qualidade de vida de seus membros ou daqueles que estão sob sua guarda.

O acesso ao capital social ${ }^{19}$ produzido nos grupos constitui uma busca e uma vantagem para os membros da RSV, uma vez que recebem acolhimento e têm acesso à troca de ideias com pessoas que passaram por processos semelhantes. 
A velocidade de propagação de uma postagem numa RSV e sua capacidade de chegar instantaneamente a qualquer indivíduo com acesso à internet tem o potencial de unir pessoas que viveram ou vivem situações reais. Hall ${ }^{3}$ informa que a mensagem é compreendida como um bem simbólico e que os constructos sociais e culturais de cada membro das RSVs atribui à mensagem um valor individual, tornanda-o única para cada um.

A interação no âmbito da CMI pode constituir um canal de informação, afetividade e pertencimento social, fortalecendo o estabelecimento de laços por meio da formação de uma rede com diálogo aberto e compreensão mútua. A qualidade das interações na rede de suporte interpessoal pode servir como forma de sustentação para os responsáveis por crianças com TEA ${ }^{10,11}$.

As RSVs, provavelmente, não serão capazes de substituir a experiência e o conhecimento de um profissional que está acostumado com as complexidades e especificidades de sua área de trabalho, contudo, algumas vezes, os usuários podem ter a falsa sensação de que as informações nos buscadores da internet ou as trocas de conhecimento nas RSVs podem ser suficientes para alcançar o estado de saúde que desejam. Desse modo é possível inferir que, com essa postura, podem chegar às consultas com a ideia de que a informação encontrada é a melhor para ele e que deve ser referendada pelo profissional, e quando isso não ocorre, nasce uma profunda frustração e insegurança.

Por outro lado, muitos profissionais podem ainda não ter percebido que o perfil dos usuários dos sistemas de saúde vem mudando, e que, quando um paciente traz dúvidas e propostas a respeito das condutas terapêuticas, isso pode não se tratar de um questionamento inconsequente à capacidade do profissional e sim, em geral, de abrir um caminho de coparticipação, corresponsabilização e cooperação entre paciente e profissional, algo que se materializa na presença de um paciente mais ativo e participativo - fenômeno intitulado "paciente informado" -, que altera as formas de governança no campo da saúde, demonstrando assim a influência das RSVs ${ }^{4,7,8}$.

Ao mesmo tempo em que internet e RSVs podem promover armadilhas aos usuários de modo que estes interpretem as informações, discussões e relatos de experiência de maneira radical e desprovida de visão crítica, há muitas interações, principalmente as trocas de experiências que possibilitam aos participantes interação, socialização e informação em saúde, que oferecem potencial para aquisição de conhecimentos e busca por melhores condições de saúde e qualidade de vida. Isso indica que a organização de usuários e profissionais de saúde em ambientes virtuais tende a se ampliar no futuro.

Nesse sentido, a construção de laços e de capital social por parte dos membros das RSVs que compartilham similaridades em suas trajetórias pessoais demonstra o potencial de gerar empoderamento aos seus usuários, fazendo com que abandonem uma postura mais passiva, pautada pela relação de dominação ancorada no saber médico, e se tornem mais ativos, conscientes e participativos em seus processos de saúde, o que tende a alterar as relações entre pacientes e profissionais, impondo mudanças às formas de governança locais.

Essa clara mudança de comportamento de alguns usuários tende a alterar formas de governança em saúde, além de exigir dos profissionais da área uma nova postura que congregue a consciência de que, se o comportamento do paciente mudou, é provável que seja necessário abandonar a postura ancorada no saber médico, excessivamente técnico e de difícil linguagem para o público em geral, bem como estabelecer a confiança entre paciente e profissional de modo a transmitir segurança e confiança às partes. Assim, os profissionais de saúde conseguirão desconstruir mitos e informações inadequadas que porventura tenham sido encontradas ou compartilhadas na internet e/ou nas RSVs.

\section{Considerações finais}

Nas RSVs abordadas nesse estudo predominam as interações mútuas, uma vez que ocorre intensa troca de informações entre seus membros, condição facilitada pela atuação das moderadoras. Nas três comunidades investigadas, nota-se que as responsáveis pela mediação das discussões nos grupos assumem um papel essencial, executando função normativa/regulamentadora, selecionando os conteúdos de maneira crítica, 
sem permitir o compartilhamento e discussão de conteúdos inadequados que possam gerar sofrimento aos demais participantes. Ao mesmo tempo, possuem a capacidade de estimular as trocas, chamando membros para relatar suas experiências conforme o tema discutido, o que possibilita que todos os participantes interessados naquele tópico de discussão possam participar, evitando digressões e fugas do tema principal.

Os participantes mais experientes acolhem e socializam conhecimentos e experiências, enquanto os mais novos trazem informações atualizadas, novas concepções, pesquisas e legislação, numa troca que ajuda a esclarecer inúmeras dúvidas. Dessa forma, tendo em vista a heterogeneidade dos membros, a relação que surge das interações tende a ser positiva para ambas as partes.

Nesse contexto, os usuários dos serviços de saúde e participantes das RSVs estão assumindo e reafirmando novos e importantes papéis perante os profissionais da saúde na governança dos processos de saúde-doença por meio da aquisição de informações proporcionada pela troca de conhecimento e experiências nas redes.

O empoderamento que se dá por meio da apropriação de informação e conhecimento nas RSVs tem alterado as formas de interação entre os usuários e profissionais dos serviços de saúde, levando ao surgimento do paciente informado, caracterizado como o usuário de saúde que possui um conjunto de conhecimentos que lhe possibilita participar de modo mais ativo nos processos que envolvem a própria saúde, conforme pode ser verificado nos dados coletados ${ }^{7,8}$.

Contudo, a interpretação incorreta de informações encontradas na internet, o compartilhamento de dados sem embasamento teórico ou a generalização de condutas para diferentes pacientes podem colocar os participantes das RSVs em risco, o que ressalta a importância dos profissionais de saúde, ao mesmo tempo em que impõe o desafio de convencer o paciente de que nem toda informação na internet é segura ou adequada ao seu contexto.

Face aos inúmeros desafios que a nova realidade impõe, e ainda tendo que enfrentar os julgamentos daqueles que estão no entorno, parece razoável que as famílias procurem ajuda daqueles que passam ou passaram por processos semelhantes, onde quer que estejam, utilizando os recursos da CMI. A organização de grupos pela internet facilita esse encontro, evidenciando que essa nova forma de interação pode favorecer a busca por novos sentidos à vida, promovendo o êxito em diversas ações sociais ${ }^{11}$.

No outro extremo, nota-se a dificuldade da sociedade em lidar com a diferença, apesar das políticas inclusivas existentes, salta aos olhos a sensação de desamparo que os responsáveis por crianças e adolescentes com TEA sentem em relação à sociedade. Os dados encontrados permitem inferir que as interações nas redes favorecem a aquisição de conhecimentos, tornando-se uma vantagem aos membros que, uma vez acolhidos, têm acesso à troca de ideias e dicas com pares sobre atividades da vida diária, conteúdos científicos e legislações, o que tende a mudar o perfil desses indivíduos quando acessam os serviços de saúde, passando a demonstrar postura mais ativa frente aos profissionais e aos próprios processos em busca dos estados de saúde que desejam.

As RSVs demonstraram que têm muito a contribuir com a busca de qualidade de vida desse público específico, uma vez que fomentam a busca por mais interação, conhecimento e informação, tiram seus membros do isolamento social e proporcionam aos participantes a capacidade de abandonar uma posição meramente passiva frente aos profissionais da saúde, favorecendo o empoderamento daqueles que delas participam e influenciando as formas de governança em saúde. Por esse motivo, um estudo mais aprofundado dos significados atribuídos a elas por esses participantes se justifica.

Visto que demonstram forte impacto no comportamento dos usuários dos serviços de saúde, essas novas formas de interação e busca por informação não podem ser ignoradas pelos decisores políticos, administradores de aparelhos de saúde e profissionais.

Recomenda-se a realização de estudos que investiguem o impacto dessa mudança de comportamento dos membros das RSVs nas formas de governança local e na relação entre pacientes e profissionais de saúde. 


\section{Referências}

1. Castells M. A sociedade em rede. São Paulo: Paz e Terra; 1999.

2. Recuero R. Comunidades virtuais em redes sociais: uma proposta de estudo. E-Compós. Dez 2005;4. doi: https://doi.org/10.30962/ec.57.

3. Hall S. Codificação/decodificação. In: Sovik L, organizador. Da diáspora: identidades e mediações culturais. Belo Horizonte: Editora UFMG; 2003. p. 365-380.

4. Buss PM, Machado JMH, Gallo E, Magalhães DP, Setti AFF, Franco NFA. Governança em saúde e ambiente para o desenvolvimento sustentável. Ciênc. Saúde Coletiva [Internet]. 2012 junho [citado em 2019 Abr 14];17(6):1479-1491. Disponível em: http://www.scielo.br/scielo.php?script=sci arttext\&pid=S141381232012000600012\&lng=en. doi: http://dx.doi.org/10.1590/S1413-81232012000600012.

5. Melo MABC. Ingovernabilidade: desagregando o argumento. In: Valladares L, organizador. Governabilidade e pobreza. Rio de Janeiro: Ed. Civilização Brasileira; 1995.

6. Valoura LD. Paulo Freire, o educador brasileiro autor do termo empoderamento, em seu sentido transformado. [Internet]. Instituto Paulo Freire. [citado em 2019 Abr 17] Disponível em: http://www. paulofreire.org/pub/Crpf/CrpfAcervo000120/Paulo Freire e o conceito de empoderamento.pdf.

7. Donaldson L. Expert patients usher in a new era of opportunity for the NHS. British Medical Journal. 2003;326(7402):1279-80.

8. Pereira NA, Barbosa L, Silva A, Dantas MLG. O paciente informado e os saberes médicos: um estudo de etnografia virtual em comunidades de doentes no Facebook. Hist Cienc Saude - Manguinhos. 2015 dez;22(Suppl):1653-71.

9. American Psychiatric Association. Manual diagnóstico e estatístico de transtornos mentais: DSM-5. Nascimento MIC, tradutor. Porto Alegre: Artmed; 2014. xliv, 948 p.

10. Sprovieri MHS, Assumpção Jr FB. Dinâmica familiar de crianças autistas. Arquivos de Neuropsiquiatria [Internet]. 2001 [citado em 2019 Abr 17]; 59(2-A):230-237. Disponível em http://www.scielo.br/pdf/anp/ v59n2A/a16v592a.pdf.

11. Sanchez FIA, Batista MN. Avaliação familiar, sintomatologia depressiva e eventos estressantes em mães de crianças autistas e assintomáticas. Contextos Clínic [Internet]. 2009 [citado em 2019 Abr 17];2(1):40-50. Disponível em: http://pepsic.bvsalud.org/scielo.php?script=sci arttext\&pid=S198334822009000100005\&lng=pt\&nrm=iso.

12. Rheingold H. The virtual community: homesteading on the electronic frontier. Reading: Addison-Wesley; 1993.

13. Oeiras JYY Rocha, HV. Uma modalidade de comunicação medida por computador e suas várias interfaces. Workshop sobre Fatores Humanos em Sistemas Computacionais; 2000; Porto Alegre: Instituto de Informática da UFRGS; 2000.

14. Wasserman S, Faust K. Social Network Analysis. Methods and Applications. Cambridge, UK: Cambridge University Press; 1994.

15. Granovetter M. The strength of weak ties. The American Journal of Sociology. 1973;78(6):1360-80.

16. Kaufman D. A força dos "laços fracos" de Mark Granovetter no ambiente do ciberespaço. Galáxia (São Paulo, Online); Jun. 2012;23:207-21.

17. Goffman E. Estigma: notas sobre a manipulação da identidade. Rio de Janeiro: LTC; 1988.

18. Bourdieu P. Os três estados do capital cultural. In: Nogueira MA, Catani A, organizadores. Escritos de educação. 2 ed. Petrópolis: Vozes; 1998. p. 71-79.

19. Roso A, Romanini M. Empoderamento individual, empoderamento comunitário e conscientização: um ensaio teórico. Psicologia e Saber Social. 2014;3(1):83-95.

20. Garbin HBR, Pereira NAF, Guilam MCR. The internet, expert patients and medical practice: an analysis of the literature. Interface (Botucatu) [Internet]. 2008 Sep [citado 2019 abril 16];12(26):579-588. doi: http://dx.doi.org/10.1590/S1414-32832008000300010.

21. Santos MHC. Governabilidade, governança e democracia: criação da capacidade governativa e relações executivo-legislativo no brasil pós-constituinte. DADOS - Revista de Ciências Sociais. 1997;40(3):335-376. 
22. Rosenau J. Governança, ordem e mudança na política mundial. In: Rosenau J, Czempiel EO. Governança sem governo: ordem e transformação na política mundial. Brasília, DF: UNB; 2000.

23. Jovell AJ, Navarro Rubio MD, Fernández Maldonado L, Blancafort S. Nuevo rol del paciente en el sistema sanitario. Atención Primaria. 2006;38(3):234-7.

24. Smith R. The future of healthcare systems. BMJ;1997;314:1495-1496.

25. Costa JH. Stuart Hall e o modelo "encoding and decoding": por uma compreensão plural da recepção. Espaço Acadêmico. Set. 2012;12(136):111-21.

26. Montardo SP, Passerino L. Inclusão social via acessibilidade digital: proposta de inclusão digital para Pessoas com Necessidades Especiais (PNE). E-Compós. 2007:8. doi: https://doi.org/10.30962/ec.144.

27. Instituto Brasileiro de Geografia e Estatística. Pesquisa Nacional por Amostra de Domicílios: síntese de indicadores. Rio de Janeiro: IBGE; 2002. 